\title{
Photocorrosion of ZnO Single Crystals during Electrochemical Water Splitting
}

\author{
Dominik Dworschak, Carina Brunnhofer, and Markus Valtiner*
}

Cite This: ACS Appl. Mater. Interfaces 2020, 12, 51530-51536

Read Online

ABSTRACT: Degradation and dissolution of transparent semiconducting oxides is central to various areas, including design of catalysts and catalysis conditions, as well as passivation of metal surfaces. In particular, photocorrosion can be significant and plays a central role during photoelectrochemical activity of transparent semiconducting oxides. Here, we utilize an electrochemical flow cell combined with an inductively coupled plasma mass spectrometer (ICP-MS) to enable the in situ study of the timeresolved release of zinc into solution under simultaneous radiation of UVlight. With this system we study the dissolution of zinc oxide single crystals with (0001) and $(10 \overline{1} 0)$ orientations. At acidic and alkaline $\mathrm{pH}$, we

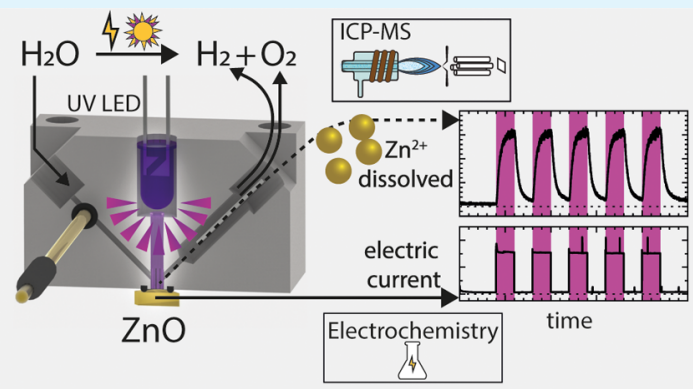
characterized potential dependent dissolution rates into both the oxygen and the hydrogen evolving conditions. A significant influence of the UV radiation and the $\mathrm{pH}$ of the electrolyte was observed. The observed dissolution behavior agrees well with the surface chemistry and stabilization mechanism of $\mathrm{ZnO}$ surfaces. In particular, polar $\mathrm{ZnO}(0001)$ shows ideal stability at low potentials and under hydrogen evolution conditions. Whereas $\mathrm{ZnO}(10 \overline{10})$ sustains higher dissolution rates, while it is inactive for water splitting. Our data demonstrates that surface design and fundamental understanding of surface chemistry provides an effective path to rendering electroactive surfaces stable under operating conditions. KEYWORDS: $\mathrm{ZnO}$, photocorrosion, photoelectrochemistry, water splitting

\section{INTRODUCTION}

Degradation and dissolution of oxide materials plays a central role in the kinetics of degradation of structural, as well as functional, materials. For instance, in photoelectrochemical cells transparent semiconducting oxides create electron-hole pairs, which can trigger electrocatalytic processes, such as water splitting. Zinc oxide $(\mathrm{ZnO})$ is considered as a promising material carrier, as well as reactive material for water splitting and other catalytic processes. ${ }^{1-3}$ With a bandgap of $3.3 \mathrm{eV}^{4}-$ close to the wavelength of visible light- $\mathrm{ZnO}$ can also effectively harvest energy from sunlight. ${ }^{1,5-10}$ Specifically, photon absorption can generate electron $\left(\mathrm{e}^{-}\right) /$hole $\left(\mathrm{h}^{+}\right)$ pairs as follows:

$$
\mathrm{ZnO}+h \nu \rightarrow \mathrm{ZnO}+\mathrm{h}^{+}+\mathrm{e}^{-}
$$

These electron/hole pairs function as driving force for photocatalytic processes; however, they also render $\mathrm{ZnO}$ prone to photocorrosion according to the following equation:

$$
\mathrm{ZnO}+2 \mathrm{~h}^{+} \rightarrow \mathrm{Zn}^{2+}+\frac{1}{2} \mathrm{O}_{2}
$$

Yet, stability under catalytic/reactive conditions is of enormous importance for efficient catalytic action. Degradation of catalysts can render them useless within a few cycles during operation. In addition to photocatalytic stability, $\mathrm{ZnO}$ is a central protective oxide in the field of corrosion protection. ${ }^{11}$
Sacrificial metallic zinc coatings are typically used as cathodic protection, and the topmost layer is passivated, that is, rendered stable by a $\mathrm{ZnO}$ layer. ${ }^{12,13}$

Consequently, stability of $\mathrm{ZnO}$ has been studied in great detail under various conditions and for various surface orientations, such as the polar ${ }^{14-21}$ and nonpolar, ${ }^{19,22}$ that is, stoichiometric, surfaces.

The polar surfaces of $\mathrm{ZnO}$ are particularly interesting in terms of their stabilization mechanisms. Several experimental and theoretical studies showed that polar surfaces can stabilize by adsorption of $\mathrm{OH}$ and oxygen adatoms, ${ }^{14,15,17}$ as well as by formation of triangular reconstructions ${ }^{18,21}$ that realize a stabilizing coverage by oxygen step-atoms.

The stability of nonpolar $\mathrm{ZnO}$ (e.g., 10י) has not been studied in great detail so far. High-resolved atomic force microscopy imaging showed that dissolution of nonpolar surfaces results in dissolution topographies that favor again the formation of polar surfaces. ${ }^{19}$ Specifically, $\mathrm{ZnO}$ (1010) has been found to reconstruct under formation of stable $\mathrm{ZnO}$

Received: August 28, 2020

Accepted: October 26, 2020

Published: November 9, 2020 
(0001) and (10 $\overline{1} 0)$ surfaces. ${ }^{19,23}$ Further, some calculations identified point defects and oxygen vacancies as stabilizing features of these surfaces. ${ }^{24,25}$

In recent years, there has been growing interest in stability of $\mathrm{ZnO}$ during photocatalysis. Here, indirect effects, such as reduced photocatalytic activity ${ }^{26-28}$ as an indicator for photocorrosion rather than dissolution were studied.

The aim of our work is to directly trace down the potential dependent stability of zinc oxide for various surface orientations particularly also during photocatalytic water splitting conditions by quantifying dissolving zinc in the electrolyte in real time.

Therefore, and as shown in Figure 1, we use a photoelectrochemical flow cell with a subsequent downstream

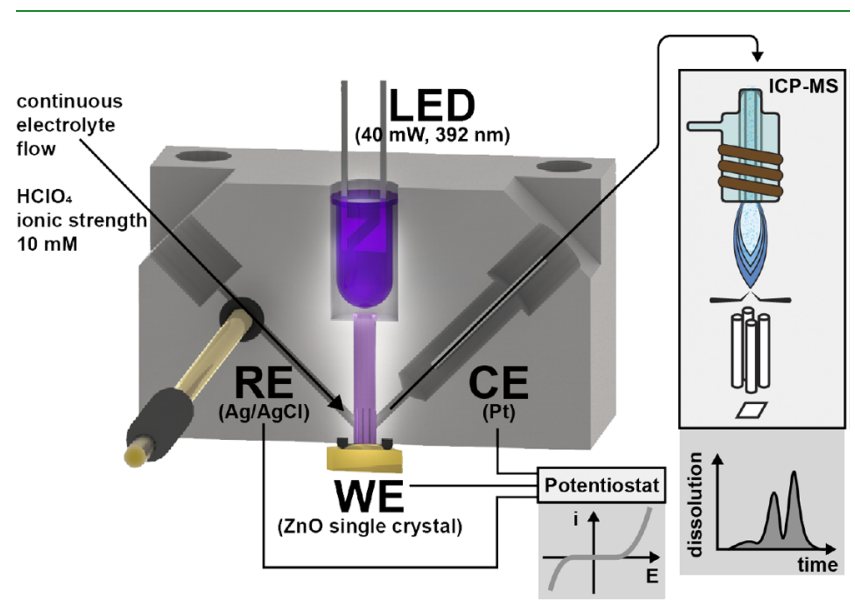

Figure 1. Schematic of the flow cell used. A quartz rod allows transmission of UV light. Overpressure pumping is used for establishing laminar flow across the working electrode. The reference electrode $(\mathrm{Ag} \mid \mathrm{AgCl})$ is placed upstream and the counter electrode $(\mathrm{Pt})$ is placed downstream to avoid contamination of platinum at the WE. Standard HPLC fittings are used for all tubings.

electrolyte analysis to determine the rate of degradation by inductively coupled plasma mass spectrometry (ICP-MS).
With its very low (essentially monolayer sensitive) limit of detection ICP-MS is a powerful technique for time-resolved analysis of degeneration products. Hence, a number of electrochemical ICP-MS flow cells have been developed for studying general metallic corrosion. ${ }^{29,30}$ Recently, this technique was adapted and tested for quantifying the photocorrosion of $\mathrm{BiVO}_{4}{ }^{31}$ and $\mathrm{WO}_{3}{ }^{32}$ as well as iridium oxide. $^{33}$

As such electrochemical ICP-MS flow cells are well established for characterizing the stability of materials that are prone to corrosion under various conditions.

Here, we use this technique to tune reaction parameters as $\mathrm{pH}$-value and applied potential regarding their influence on $\mathrm{ZnO}$ degradation rates. For the first time, we use this technique with oxide single crystals, and we are able to connect $\mathrm{ZnO}$ surface orientation chemistry with observed stability and water splitting rates. Specifically, we study the photocatalytic stability of low-index $\mathrm{ZnO}$ surfaces (0001) and $(10 \overline{10})$ in aqueous perchlorate solutions for both the oxygen evolution reaction (OER) and the hydrogen evolution reaction (HER). We show which surface is catalytically more active (higher water splitting current) and how stable the surfaces are under these conditions. The approach and the specific results offer a strategy for making $\mathrm{ZnO}$ most stable and reactive or vice versa.

\section{RESULTS}

The key question we want to address in this work is at which potential does $\mathrm{ZnO}$ degrade and how is this influenced by the surface chemistry, that is, termination of the surface? In this work, we, hence, focus on the nonpolar $(10 \overline{1} 0)$ and the polar zinc-terminated (0001)- $\mathrm{Zn}$ surfaces of $\mathrm{ZnO}$, for which we already studied stabilization mechanism and surface chemistry extensively in our previous work. ${ }^{14-17}$

We designed a home-built UV-sensitized electrochemical flow-cell (see again Figure 1) and combine this flow cell with a subsequent quantitative analysis of dissolved zinc in the electrolyte in an ICP-MS. Briefly, electrolyte solution is constantly fed through a standard three electrode electro-

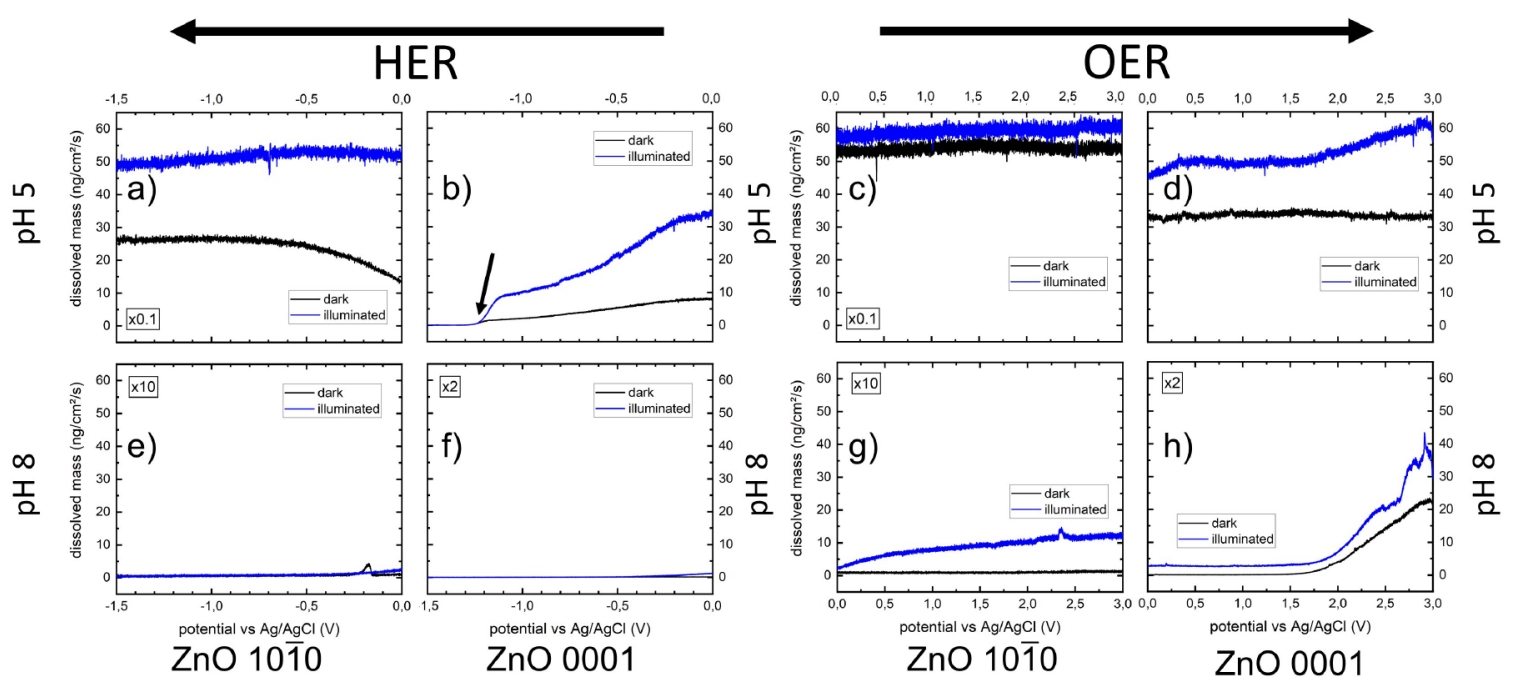

Figure 2. Dissolution rates of $\mathrm{ZnO} 0001$ and $10 \overline{1} 0$ face in $10 \mathrm{mM} \mathrm{ClO}_{4}^{-}$solutions during linear sweep voltammetry $(1 \mathrm{mV} / \mathrm{s})$. Please note that all panels are similarly scaled, but some of the data is multiplied by a constant to be visible in the plotted range, as indicated. Arrows indicate scan directions. Significantly higher dissolution rates can be observed with lower $\mathrm{pH}$ (a and b). Illumination results in higher dissolution rates (c.f., text for details). 

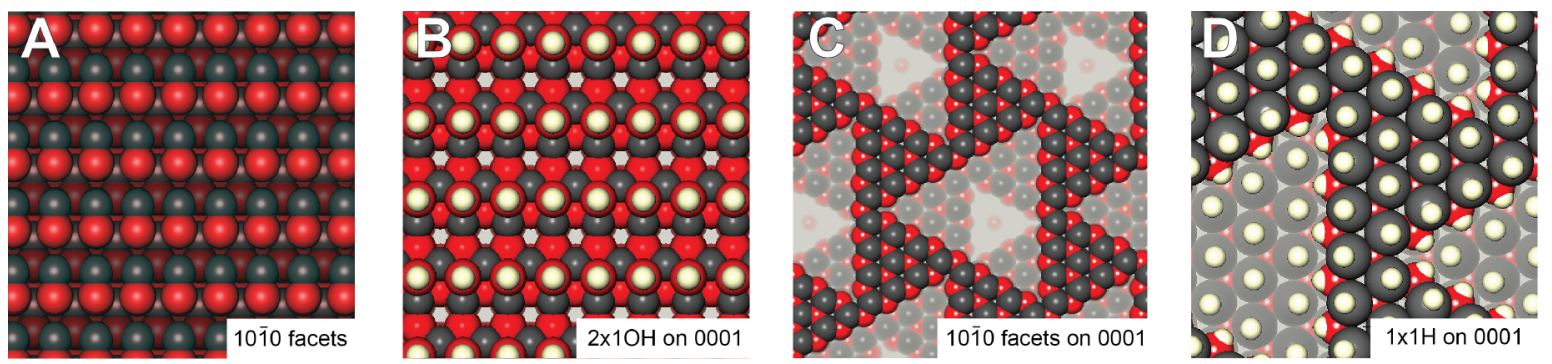

Figure 3. (A) Ideal nonpolar $\mathrm{ZnO}$ ( $10 \overline{1} 0$ surface). (B) Half coverage by hydroxide. (C) Triangular reconstruction on $\mathrm{ZnO}(0001)$. (D) Stabilization by formation of triangles of $10 \overline{1} 0$ orientation and additional coverage with a hydrogen layer. Oxygen: Red. Zinc: Black. Hydrogen: Beige.

chemical cell, where a $\mathrm{ZnO}$ single crystal acts as working electrode. UV light illuminates the surface from the top. Any dissolved zinc species are carried with the electrolyte flow toward detection in the ICP-MS. A detailed description of the cell is given in the experimental section and in previous work. $^{31-33}$

Two different $\mathrm{pH}$ values, acidic at $\mathrm{pH} 5$ and weakly alkaline at $\mathrm{pH} 8$, were chosen as operating conditions. Given the experimental and calculated Pourbaix diagram of zinc, ${ }^{34,35}$ these conditions suggest $\mathrm{Zn}^{2+}$ and $\mathrm{Zn}(\mathrm{OH})_{2}$ as dissolving/ stable species. At $\mathrm{pH} 8$, the surfaces are considered stabilized, while higher dissolution rates are expected for lower $\mathrm{pH}$ values. Experiments always started at a potential of $0.0 \mathrm{~V}$ versus $\mathrm{Agl}$ $\mathrm{AgCl}$, where no water splitting and stable surfaces are expected. We vary the potentials with a scan rate of $1 \mathrm{mV} / \mathrm{s}$ from (1) 0 to $+3.0 \mathrm{~V}$, that is, into the OER region, and (2) from 0 to -1.5 $\mathrm{V}$, which is into the region of the HER, respectively.

Figure 2 shows the dissolution of $\mathrm{ZnO}$ during linear sweep voltammetry for nonpolar $\mathrm{ZnO}$ (1010) and polar $\mathrm{ZnO}$ (0001). Blue lines indicate the dissolution during UV illumination, whereas the black data shows dissolution under dark conditions. The electric currents corresponding to the data shown in Figure 2 can be found in the Supporting Information (Figure S1). The figures indicate a number of interesting details as follows.

First, the effect of $\mathrm{pH}$ is very evident. When performed at $\mathrm{pH} 5$, both surface orientations show 1-2 orders of magnitude higher dissolution rates compared to $\mathrm{pH}$ 8. This is consistent with the expected dissolution tendencies derived from Pourbaix diagrams. $\mathrm{ZnO}$ is considered stable from $\mathrm{pH} 8$ to $\mathrm{pH} 6$ and around $0 \mathrm{~V}$ versus $\mathrm{Ag} \mid \mathrm{AgCl}$. Below $\mathrm{pH} 5$ thermodynamic instability drives the dissolution. Further, (Figure 2a, c, e, g) also show that nonpolar $\mathrm{ZnO}(10 \overline{10})$ surfaces exhibit very high dissolution rates at $\mathrm{pH} 5$ at both, HER and OER conditions, when compared to the polar $\mathrm{ZnO}$ (0001) shown in (Figure 3b, d, f, h). As emphasized, the rates for the nonpolar surface are in general about 1 order of magnitude larger compared to the polar surface, while water splitting currents are insignificant within the scanned regions toward HER and OER (see again Figure S1).

Also, both surfaces show a rather constant or increasing dissolution rate when polarizing toward OER at $\mathrm{pH} 5$. Surprisingly, at $\mathrm{pH} 5$, the polar surface shows a very significant decrease of the dissolution rate toward HER conditions (marked by arrow in Figure 2b). As soon as hydrogen evolution starts the polar surface shows insignificant dissolution rates (see Figure 2b) in acidic conditions. At $\mathrm{pH}$ 8, shown in Figure 2e and $\mathrm{f}$, both surface orientations show low dissolution rates toward the HER, which get even lower with increasing negative polarization.

Interestingly, as soon as the OER initiates at $\mathrm{pH} 8$ the polar surface shows an approximately one order of magnitude higher dissolution rate (Figure $2 \mathrm{~h}$ ) compared to the nonpolar surface (Figure $2 \mathrm{~g}$ ). Again the nonpolar surface shows no significant OER current at the applied potential, while the polar surface can split water effectively, yet at a high corrosion rate (see again Figure S1).

Second, illumination with UV light in general results in higher amount of dissolved zinc for both surface orientations. The relative increase of dissolution rates under illuminated conditions varies strongly with the $\mathrm{pH}$, applied potential and surface orientation. In the acidic case in the HER direction, for $\mathrm{ZnO}(10 \overline{10})$ (Figure 2a) illumination almost doubles the amount of dissolved $\mathrm{ZnO}$. Also, under illumination degradation seems to be constant while decreasing the potential, while it increases in the dark. Moreover, the same applies for the OER (Figure 2c) at $\mathrm{pH} 5$. Here, the dissolution reaches very high rates. Also the difference between illuminated and dark case is still about $10-50 \%$, for each surface respectively, at an already very high level.

For the OER scan at $\mathrm{pH} 8$ (Figure 2d), a significant effect of illumination was observed for both orientations. Specifically, under illumination the $\mathrm{ZnO}$ dissolution rate is growing at a low level for the $\mathrm{ZnO}(10 \overline{10})$ as the potential rises(see Figure $2 \mathrm{~g}$ ), while it is considerably higher for the polar surface. No significant oxygen evolution accompanies the dissolution of the nonpolar surface, while the polar surface evolves oxygen. In contrast, under dark conditions at $\mathrm{pH} 8$ dissolution remains negligible over the whole potential window. As already pointed out above, for the polar surface (Figure $2 \mathrm{~d}$ and $\mathrm{h}$ ), the dissolution rate is considerably higher compared to the nonpolar surface at positive polarization, also during illumination.

At negative polarization at $\mathrm{pH} 8$, the effect of illumination is insignificant for both surface orientations (Figure $2 e$ and $f$ ), and the $\mathrm{Zn}$ dissolution drops below the limit of detection at hydrogen evolution.

\section{DISCUSSION}

The key to understanding the observed behavior of the different $\mathrm{ZnO}$ facets is to consider the stabilization and dissolution mechanism of the facets.

Considering the wurtzite structure of $\mathrm{ZnO}$, along its $c$-axis $\mathrm{ZnO}$ is made up of alternating layers of hexagonal close-packed $\mathrm{Zn}^{2+}$ and $\mathrm{O}^{2-}$ resulting in a O-terminated surface on one and a $\mathrm{Zn}$-terminated on the opposing side. This generates a diverging dipole across a crystal, and will render the polar $\mathrm{ZnO}(0001)-$ 

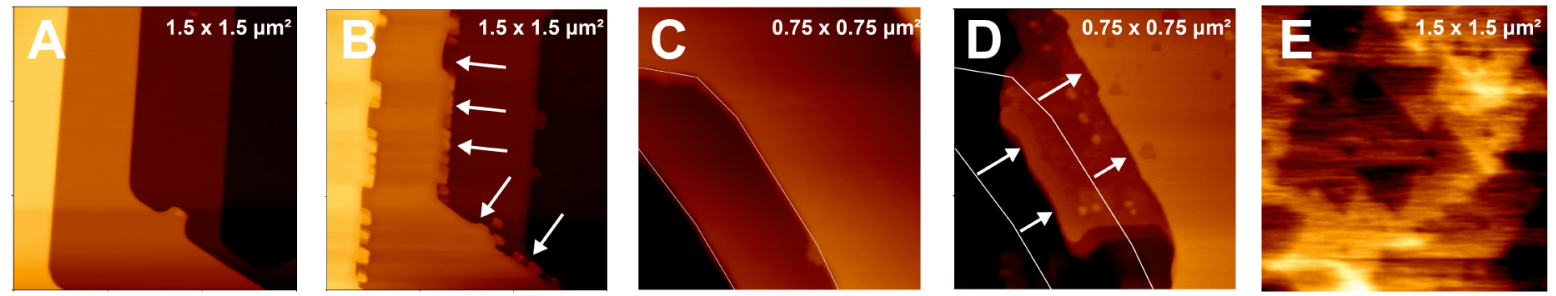

Figure 4. In-situ AFM topographies indicate preferential dissolution of $10 \overline{1}$ step edge surfaces on a (0001) surface (marked by arrows) upon decrease of the $\mathrm{pH}$ values from $(\mathrm{A} / \mathrm{B}) \mathrm{pH} 8-6$ and $(\mathrm{C} / \mathrm{D}) \mathrm{pH} 8$ to $\mathrm{pH}$ 3. Panel $\mathrm{E}$ shows an ex-situ topography after immersion into a pH 3 solution, indicating stabilization by formation of triangles with step edges of (10ī0) orientation on (0001) surfaces (c.f., text for details).

Zn prone stabilizing reconstructions. ${ }^{15,21}$ Specifically, the dipole through the crystal has to be eliminated by triangular reconstruction or adsorption of adatoms on the surface. ${ }^{15,21,36}$ In contrast other low index surface orientations have stoichiometric $\mathrm{ZnO}$ terminations and do not exhibit complex reconstructions.

The resulting surface structures for the polar and the nonpolar surface are shown in Figure 3. As displayed in panel $\mathrm{A}$, the ideal nonpolar $\mathrm{ZnO}(10 \overline{10})$ surface consists of rows of $\mathrm{ZnO}$ pairs, hence displaying both under-coordinated yet stoichiometric $\mathrm{Zn}$ and $\mathrm{O}$ adatoms at the surface. Panel $\mathrm{B}$ shows a possible $(2 \times 1) \mathrm{OH}$ adsorption layer, that can stabilize the polar Zn-terminated surface in alkaline ${ }^{15}$ and water-rich media, ${ }^{14,16}$ and panel $\mathrm{C}$ shows an alternative possibility to stabilize the polar surface. ${ }^{21}$ Here, triangular features are formed, which also offer oxygen atoms in a stoichiometric concentration to stabilize the surface. Panel D shows a similar surface reconstruction, but triangles and stepedge oxygen atoms are covered with a hydrogen layer. The latter structure is thermodynamically stable under hydrogenrich conditions. ${ }^{17}$

In our previous work ${ }^{14}$ and in Figure 4, we now show how a $\mathrm{ZnO}(0001)$ surface dissolves when lowering the $\mathrm{pH}$ from 8 to acidic conditions. The in situ AFM series, recorded with two different single crystals, in Figure $4 \mathrm{~A}-\mathrm{D}$, shows persistence of 0001 terraces, where degradation/dissolution occurs along the step edges, which are nonpolar surfaces. This confirms, that the nonpolar step edge surfaces are considerably more unstable compared to the stabilized polar surface. This is consistent with the observed higher dissolution rate of the nonpolar surface at low $\mathrm{pH}$ and all potentials.

Figure 4E shows the polar surface after extensive etching in acidic conditions. Here, a surface reconstruction with triangular features on the (0001) surface becomes visible. This is what we previously observed and indicates a kinetic stabilization of the surface by formation of triangular features, which have no kink sites. ${ }^{14}$ This slows down dissolution rates significantly.

These triangular features are, hence, the reason for the lower dissolution rates at $\mathrm{pH} 5$ of the polar surface when compared to the nonpolar surface, as observed for the potential dependent data above. The nonpolar surface is not stabilized and indicates dissolution rates that are at least 1 order of magnitude higher at $\mathrm{pH} 5$.

Interestingly, for the polar surface Figure 4D also shows that lowering the $\mathrm{pH}$ results in holes (marked) before typical triangular features appear. These holes indicate that the stabilizing $\mathrm{OH} / \mathrm{O}$ adlayer dissolves at lower $\mathrm{pH}$, which effectively forces the polar surface into a different stabilization mechanism shown in Figure 4E.
Furthermore, the sudden drop of dissolution of the polar surface during negative polarization in acidic conditions in Figure $3 \mathrm{~b}$ suggests a protecting adsorption of hydrogen on the (0001) surface structure as indicated in Figure 3D. Here, under active HER conditions, where hydrogen must adsorb on the surface, the proposed $1 \mathrm{H}(1 \times 1)$ adsorption layer ${ }^{17,37}$ on $\mathrm{ZnO}(0001)-\mathrm{Zn}$ does lead to a stabilization of the surface under active and hydrogen-rich conditions. Indeed, also our previous theoretical investigations showed that $(1 \times 1)-\mathrm{H}$ coverage can be an effective surface stabilization at hydrogenrich conditions. ${ }^{17}$ Hence, correlation of phase diagrams and experimentally observed stability with ICP-MS flow cells proves to be beneficial for designing stable materials.

Specifically, the data suggests that hydrogen effectively stabilizes $\mathrm{ZnO}(0001)$ by a theoretically predicted $(1 \times 1)$ - $\mathrm{H}$ adsorption on $\mathrm{Zn}$ and step edge atoms of the typical triangular reconstructions. Direct evidence of $1 \times 1 \mathrm{H}$ adsorption on polar $\mathrm{ZnO}$ at solid/liquid interfaces is currently not feasible to obtain; however, in future studies, we aim to utilize AFM/ STM imaging at the solid/liquid interface to provide a direct experimental evidence. The applied overpotential in the experiment suggests that the conditions in this work are capable to achieve conditions, where $\mathrm{ZnO}(0001)-\mathrm{Zn}$ is indeed stabilized by this $(1 \times 1)$ - $\mathrm{H}$ adlayer, which is stable in extended ab initio phase diagrams under reactive conditions. ${ }^{17}$ Consequently, the sudden drop of the dissolution rate may coincide with the theoretically predicted $(1 \times 1)-\mathrm{H}$ hydrogen adsorption. This suggests an operating condition on the $\mathrm{ZnO}(0001)$ surface, where hydrogen evolution proceeeds under conditions that thermodynamically stabilize the surface by $(1 \times 1)-\mathrm{H}$ coverage, while water is beyond its thermodynamic stability. This effectively renders the surface inert against degradation under reactive water splitting conditions. This is an interesting mechanistic insight and may prove useful for designing other stable surfaces under operating conditions.

Conversely, in the alkaline case, the low dissolution rate (seen in Figure 2f) correlates well with the expected $\mathrm{OH}$ coverage of the $\mathrm{ZnO}(0001)-\mathrm{Zn}$ surface (Figure $3 \mathrm{~B}$ ) and the general thermodynamic stability of $\mathrm{ZnO}$.

A very interesting aspect at $\mathrm{pH} 8$ is that the polar $\mathrm{ZnO}(0001)$ surface is less stable compared to the nonpolar surface under oxygen evolving conditions. This is unexpected, as one would expect that oxygen rich conditions stabilize triangular reconstructions on the polar surfaces. This has two reasons.

First, oxygen evolution on polar $\mathrm{ZnO}(0001)$ may proceed via a direct reaction of water with step edge oxygen atoms or stabilizing $\mathrm{OH}$ adatoms. As such, the stabilizing features will dissolve during oxygen evolution, which makes the surface less stable and prone to corrosion under reactive conditions. Why 
dissolution is less significant for the nonpolar surface is then evident. On this surface, the oxygen evolution does not proceed at a significant rate at all, the observed dissolution is solely due to the applied potential for the intrinsically thermodynamically stable nonpolar surface at $\mathrm{pH} 8$.

Second, UV irradiation also triggers dissolution of the polar $\mathrm{ZnO}$ surface at $\mathrm{pH} 8$, under any condition above about $0 \mathrm{~V}$, while the nonpolar is significantly less prone to photocorrosion. For the polar surface, this is also well visible in $\mathrm{UV}$ on/off experiments recorded at $\mathrm{pH} 8$ at $1.5 \mathrm{~V}$, which are shown in Figure 5. This is interesting, as $\mathrm{ZnO}$ is in principle

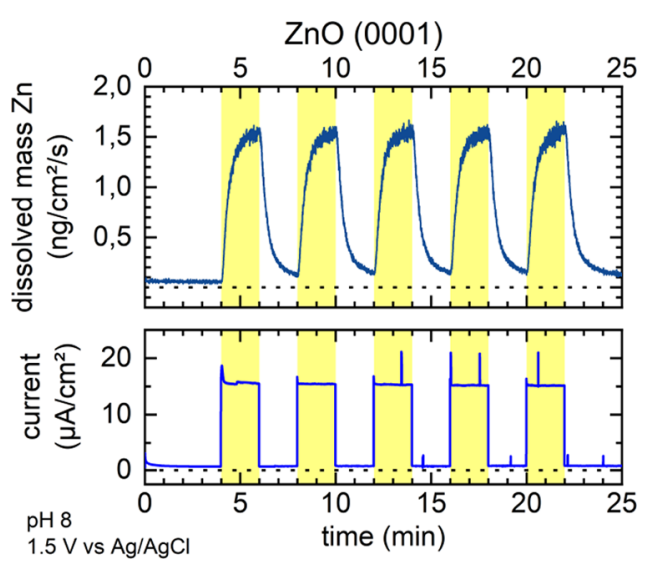

Figure 5. Dissolution and electric current of a $\mathrm{ZnO}$ (0001) surface held at $1.5 \mathrm{~V}$ versus $\mathrm{Ag} \mid \mathrm{AgCl}$ in perchlorate solution at $\mathrm{pH} 8$, while UV light is switched on (yellow areas) and off. Dissolution and current response on UV exposure is clearly visible.

thermodynamically stable at $\mathrm{pH}$ 8. Hence, holes, $\mathrm{h}^{+}$, can apparently interact with the stabilizing electronic surface states of the $\mathrm{ZnO}(0001)$ surface, forcing it into dissolution via eq 2 .

UV irradiation was generally found to increase the rate of dissolution. This is likely via amplification of eq 2 . Generated holes can oxidize the oxygen in the semiconductor to its molecular form, while releasing zinc ions into solution. This process competes with the desired water splitting reactions, and drives the dissolution under all conditions, with the exception of $\mathrm{ZnO}(0001)$ under hydrogen-rich conditions at low potentials. This is again in line with the stabilization mechanism of the polar surface via hydrogen adsorption on terraces and step edges. ${ }^{17}$

Interestingly, the stabilization of hydrogen on the polar surface also results in the highest rate of hydrogen evolution (see currents in the Supporting Information), yet at the lowest dissolution rate under both illuminated and dark conditions. As such, these results strongly support the idea that hydrogen stabilized polar surface structures on semiconducting oxides can effectively moderate hydrogen evolution under stable conditions. As such, transition metal coverage, $\mathrm{ZnO}(0001)$, or other polar surfaces may be an interesting candidate for a stable hydrogen evolution catalyst.

In contrast oxygen evolving conditions render $\mathrm{ZnO}(0001)$ unstable, with the ongoing OER the dissolution rate of $\mathrm{ZnO}$ increases in concert at $\mathrm{pH} 5$ and 8 . This again indicates a mechanism that proceeds via dissolution of oxygen step atoms. Interestingly, at $\mathrm{pH} 8$ under OER conditions the nonpolar surface appears more stable, but oxygen evolution rates are insignificant at the tested potentials, indicating a large overpotential for the OER on the nonpolar surface.

\section{CONCLUSIONS}

In summary, stabilization of the $\mathrm{ZnO}(0001)-\mathrm{Zn}$ surface in both acidic and alkaline aqueous electrolytes was studied by means of a photoelectrochemical flow cell with consecutive detection of degradation products via ICP-MS. The wellknown polar surface stabilization mechanisms ${ }^{14,16,18,21}$ seem to also apply for photoelectrochemical conditions. The time and potential-resolved dissolution study on polar and nonpolar zinc oxide revealed the following conclusions:

- $\mathrm{ZnO}$ is prone to photocorrosion by ultraviolet light to different extents depending on their orientation.

- However, polar $\mathrm{ZnO}(0001)$ can stabilize during HER via formation of protective $(1 \times 1)$-H layer in acidic and $(2 \times 1)-\mathrm{OH}$ in alkaline electrolyte. This structure also support highest measured hydrogen evolution currents, yet under very stable conditions. In contrast, nonpolar $\mathrm{ZnO}$ shows no significant hydrogen evolution, yet high dissolution at HER potentials.

- Nonpolar $\mathrm{ZnO}$ is in general less stable compared to polar $\mathrm{ZnO}$ for all $\mathrm{pH}$ values and potentials probed. The exception to this is oxygen evolution at $\mathrm{pH}$ 8. Under these conditions, the nonpolar surface is more stable but also evolves no oxygen. This may make this surface orientation interesting for a carrier material under these conditions.

- Extended ab initio phase diagrams correlate well with experimentally observed stabilities beyond the stability of the water phase, suggesting that phase diagrams are an ideal tool for screening stable candidate surfaces outside the water stability window. This region is not typically evaluated in this type of simulations.

Our approach for testing photocatalysts during operation on photocorrosion might prove useful for further and more complex systems. In addition, our results highlight that surface design (facet preferences and stabilization mechanism of oxides) can provide an effective path to making (photo)electrocatalytic (support) surfaces more stable during reactive conditions. Stabilization mechanisms of polar surfaces may provide an effective path to tuning stability of transition metal oxides under electrochemical and photoelectrochemical conditions.

\section{METHODS AND MATERIALS}

Chemicals and Materials. A $10 \mathrm{mM}$ solution was prepared from sodium perchlorate ( $98+\%$, Alpha Aesar). $\mathrm{pH}$ was adjusted using sodium hydroxide (technical, VWR) and perchloric acid (p.a. grade, Carl Roth), while maintaining the concentration of the perchlorate anion constant. Milli- $\mathrm{Q}$ water (resistivity $>18 \mathrm{M} \Omega \cdot \mathrm{cm}$, total organic carbon $<4 \mathrm{ppb}$ ) was used for making electrolyte solutions. $\mathrm{ZnO}$ single crystals (MaTecK GmbH) of orientations (0001) and (1010) were prepared by hand polishing using diamond paste down to 0.05 $\mu \mathrm{m}$.

Inductively Coupled Plasma Mass Spectrometry (ICP-MS). Measurements were performed using an Agilent 7900 ICP-MS. The ICP-MS uses a collision cell with $5 \mathrm{~mL} / \mathrm{min}$ flow of helium as cell gas. External calibration was performed with multielement standard solutions provided by Agilent and Inorganic Ventures. Downstream of the electrochemical cell the analyte was mixed with internal standard solutions containing cobalt having a similar mass as zinc.

A scheme of the setup is shown in Figure 1. The in-house built electrochemical flow cell was made out of PTFE. The cell is illuminated by a UV LED (UV5TZ-390-15, Bivar, Inc.) shining through a quartz rod from the top on the active working electrode area. The illuminated area is at least $3.14 \mathrm{~mm}^{2}$ ( $2 \mathrm{~mm}$ diameter rod) 
neglecting any scattering of UV light. Total electrode area is about 7 $\mathrm{mm}^{2}$ (3 $\mathrm{mm}$ diameter O-ring). Pressurized air was used for pumping the electrolyte with a stable and pulsation free laminar flow. Flow was monitored by measuring with an in-flow pressure sensor and by weighing the collected waste electrolyte. The flow is set to $6 \pm 0.4 \mathrm{mg}$ of solution per second. Before each experiment the electrolyte was purged with compressed and filtered air for at least $30 \mathrm{~min}$ to guarantee the same concentration of dissolved oxygen. All electrochemical experiments were done using a $\mathrm{Ag} / \mathrm{AgCl}$-electrode as reference and presented data is referenced to that potential.

Atomic Force Microscopy (AFM). AFM topography (JPK) experiments were perfomed using contact mode cantilevers (Budget Sensor CONT). Using a custom-made cell for liquids of PEEK, electrolyte was exchanged with a syringe pump.

\section{ASSOCIATED CONTENT}

\section{st Supporting Information}

The Supporting Information is available free of charge at https://pubs.acs.org/doi/10.1021/acsami.0c15508.

Electric currents corresponding to dissolution shown in Figures 2 and 3 (PDF)

\section{AUTHOR INFORMATION}

\section{Corresponding Author}

Markus Valtiner - Vienna University of Technology, Institute for Applied Physics, A-1040 Vienna, Austria; 이이.org/ 0000-0001-5410-1067; Email: markus.valtiner@ tuwien.ac.at

\section{Authors}

Dominik Dworschak - Vienna University of Technology, Institute for Applied Physics, A-1040 Vienna, Austria; (1) orcid.org/0000-0002-7585-767X

Carina Brunnhofer - Vienna University of Technology, Institute for Applied Physics, A-1040 Vienna, Austria

Complete contact information is available at:

https://pubs.acs.org/10.1021/acsami.0c15508

\section{Notes}

The authors declare no competing financial interest.

The raw and processed data required to reproduce these findings are available from the corresponding author via https://repositum.tuwien.ac.at upon reasonable request.

\section{ACKNOWLEDGMENTS}

The authors acknowledge support by the European Research Council (Grant CSI.interface, ERC-StG 663677, characterization of surfaces). M.V. and C.B. gratefully acknowledge support from the K1-COMET center CEST (Centre for Electrochemical Surface Technology, Wiener Neustadt) funded by the Austrian Research Promotion Agency (FFG). The authors acknowledge the TU Wien University Library for financial support through its Open Access Funding Program.

\section{REFERENCES}

(1) Fekete, M.; Riedel, W.; Patti, A. F.; Spiccia, L. Photoelectrochemical Water Oxidation by Screen Printed $\mathrm{ZnO}$ Nanoparticle Films: Effect of $\mathrm{pH}$ on Catalytic Activity and Stability. Nanoscale 2014, 6, 7585-7593.

(2) Hakimian, A.; McWilliams, S.; Ignaszak, A. ZnO Synthesized Using Bipolar Electrochemistry: Structure and Activity. Materials 2019, 12, 535.

(3) Jiang, J.; Wang, Y.; Ren, W.; Xie, Y.; Chen, Y. Surface Modification of $\mathrm{ZnO}$ Microrod Arrays Films by Ion-Exchange
Approach and their Photoelectrochemical Performances. Int. J. Hydrogen Energy 2018, 43, 13931-13938.

(4) Srikant, V.; Clarke, D. R. On the Optical Band Gap of Zinc Oxide. J. Appl. Phys. 1998, 83, 5447-5451.

(5) da Trindade, L. G.; Minervino, G. B.; Trench, A. B.; Carvalho, M. H.; Assis, M.; Li, M. S.; de Oliveira, A. J.; Pereira, E. C.; Mazzo, T. M.; Longo, E. Influence of Ionic Liquid on the Photoelectrochemical Properties of ZnO Particles. Ceram. Int. 2018, 44, 10393-10401.

(6) Hieu, H. N.; Vuong, N. M.; Kim, D. Optimization of CdS/ZnO Electrode for Use in Photoelectrochemical Cell. J. Electrochem. Soc. 2013, 160, H852-H857.

(7) Ida, S.; Yamada, K.; Matsunaga, T.; Hagiwara, H.; Ishihara, T.; Taniguchi, T.; Koinuma, M.; Matsumoto, Y. Photoelectrochemical Hydrogen Production from Water Using p-Type CaFe2O4 and nType ZnO. Electrochemistry 2011, 79, 797-800.

(8) Kislov, N.; Lahiri, J.; Verma, H.; Goswami, D. Y.; Stefanakos, E.; Batzill, M. Photocatalytic Degradation of Methyl Orange over Single Crystalline $\mathrm{ZnO}$ : Orientation Dependence of Photoactivity and Photostability of ZnO. Langmuir 2009, 25, 3310-3315.

(9) Mandal, H.; Shyamal, S.; Hajra, P.; Samanta, B.; Fageria, P.; Pande, S.; Bhattacharya, C. Improved Photoelectrochemical Water Oxidation using Wurtzite $\mathrm{ZnO}$ Semiconductors Synthesized through Simple Chemical Bath Reaction. Electrochim. Acta 2014, 141, 294301.

(10) Yolaçan, D.; Demirci Sankir, N. Enhanced Photoelectrochemical and Photocatalytic Properties of 3D-hierarchical $\mathrm{ZnO}$ Nanostructures. J. Alloys Compd. 2017, 726, 474-483.

(11) Marder, A. R. The Metallurgy of Zinc-coated Steel. Prog. Mater. Sci. 2000, 45, 191-271.

(12) Spathis, P.; Poulios, I. The Corrosion and Photocorrosion of Zinc and Zinc Oxide Coatings. Corros. Sci. 1995, 37, 673-680.

(13) Zhang, X. G. Corrosion and Electrochemistry of Zinc; Plenum: New York, 1996.

(14) Valtiner, M.; Borodin, S.; Grundmeier, G. Stabilization and Acidic Dissolution Mechanism of Single-Crystalline $\mathrm{ZnO}(0001)$ Surfaces in Electrolytes Studied by In-Situ AFM Imaging and ExSitu LEED. Langmuir 2008, 24, 5350-5358.

(15) Valtiner, M.; Borodin, S.; Grundmeier, G. Preparation and Characterisation of Hydroxide Stabilised $\mathrm{ZnO}(0001)-\mathrm{Zn}-\mathrm{OH}$ Surfaces. Phys. Chem. Chem. Phys. 2007, 9, 2406-2412.

(16) Valtiner, M.; Todorova, M.; Grundmeier, G.; Neugebauer, J. Temperature Stabilized Surface Reconstructions at Polar $\mathrm{ZnO}(0001)$. Phys. Rev. Lett. 2009, 103, No. 065502.

(17) Valtiner, M.; Torrelles, X.; Pareek, A.; Borodin, S.; Gies, H.; Grundmeier, G. In Situ Study of the Polar ZnO(0001)-Zn Surface in Alkaline Electrolytes. J. Phys. Chem. C 2010, 114, 15440-15447.

(18) Kresse, G.; Dulub, O.; Diebold, U. Competing Stabilization Mechanism for the Polar $\mathrm{ZnO}(0001)-\mathrm{Zn}$ Surface. Phys. Rev. B: Condens. Matter Mater. Phys. 2003, 68, 245409.

(19) Nicholas, N. J.; Ducker, W.; Franks, G. V. Differential Etching of $\mathrm{ZnO}$ Native Planes under Basic Conditions. Langmuir 2012, 28, 5633-5641.

(20) Diebold, U.; Koplitz, L.; Dulub, O. Atomic-Scale Properties of Low-Index ZnO Surfaces. Appl. Surf. Sci. 2004, 237, 336-342.

(21) Dulub, O.; Diebold, U.; Kresse, G. Novel Stabilization Mechanism on Polar Surfaces: $\mathrm{ZnO}(0001)-\mathrm{Zn}$. Phys. Rev. Lett. 2003, 90, No. 016102.

(22) Meyer, B.; Marx, D. Density-functional Study of the Structure and Stability of $\mathrm{ZnO}$ Surfaces. Phys. Rev. B: Condens. Matter Mater. Phys. 2003, 67, No. 035403.

(23) Nicholas, N. J.; Franks, G. V.; Ducker, W. A. The Mechanism for Hydrothermal Growth of Zinc Oxide. CrystEngComm 2012, 14, $1232-1240$.

(24) D’Amico, N. R.; Cantele, G.; Ninno, D. First-Principles Calculations of Clean and Defected ZnO Surfaces. J. Phys. Chem. C 2012, 116, 21391-21400.

(25) Göpel, W.; Lampe, U. Influence of Defects on the Electronic Structure of Zinc Oxide Surfaces. Phys. Rev. B: Condens. Matter Mater. Phys. 1980, 22, 6447-6462. 
(26) Tayebi, M.; Tayyebi, A.; Masoumi, Z.; Lee, B.-K. Photocorrosion Suppression and Photoelectrochemical (PEC) Enhancement of $\mathrm{ZnO}$ via Hybridization with Graphene Nanosheets. Appl. Surf. Sci. 2020, 502, 144189.

(27) Serrà, A.; Zhang, Y.; Sepúlveda, B.; Gómez, E.; Nogués, J.; Michler, J.; Philippe, L. Highly Active ZnO-based Biomimetic Fernlike Microleaves for Photocatalytic Water Decontamination using Sunlight. Appl. Catal., B 2019, 248, 129-146.

(28) Tayyebi, A.; Soltani, T.; Lee, B.-K.; Outokesh, M.; Tayebi, M. Novel Visible Light Photocatalytic and Photoelectrochemical (PEC) Activity of Carbon-doped Zinc Oxide/Reduced Graphene Oxide: Supercritical Methanol Synthesis with Enhanced Photocorrosion Suppression. J. Alloys Compd. 2017, 723, 1001-1010.

(29) Ogle, K.; Weber, S. Anodic Dissolution of 304 Stainless Steel Using Atomic Emission Spectroelectrochemistry. J. Electrochem. Soc. 2000, 147, 1770-1780.

(30) Ogle, K. Atomic Emission Spectroelectrochemistry: Real-Time Rate Measurements of Dissolution, Corrosion, and Passivation. Corrosion 2019, 75, 1398-1419.

(31) Zhang, S.; Rohloff, M.; Kasian, O.; Mingers, A. M.; Mayrhofer, K. J. J.; Fischer, A.; Scheu, C.; Cherevko, S. Dissolution of BiVO4 Photoanodes Revealed by Time-Resolved Measurements under Photoelectrochemical Conditions. J. Phys. Chem. C 2019, 123, 23410-23418.

(32) Knöppel, J.; Zhang, S.; Speck, F. D.; Mayrhofer, K. J.; Scheu, C.; Cherevko, S. Time-resolved Analysis of Dissolution Phenomena in Photoelectrochemistry - A Case Study of WO3 Photocorrosion. Electrochem. Commun. 2018, 96, 53-56.

(33) Kasian, O.; Geiger, S.; Li, T.; Grote, J.-P.; Schweinar, K.; Zhang, S.; Scheu, C.; Raabe, D.; Cherevko, S.; Gault, B.; Mayrhofer, K. J. J. Degradation of Iridium Oxides via Oxygen Evolution from the Lattice: Correlating Atomic Scale Structure with Reaction Mechanisms. Energy Environ. Sci. 2019, 12, 3548-3555.

(34) Najam Khan, M.; Al-Hinai, M.; Al-Hinai, A.; Dutta, J. Visible Light Photocatalysis of Mixed Phase Zinc Stannate/Zinc Oxide Nanostructures Precipitated at Room Temperature in Aqueous Media. Ceram. Int. 2014, 40, 8743-8752.

(35) Beverskog, B.; Puigdomenech, I. Revised Pourbaix Diagrams for Zinc at $25-300{ }^{\circ}$ C. Corros. Sci. 1997, 39, 107-114.

(36) Nyberg, M.; Nygren, M. A.; Pettersson, L. G. M.; Gay, D. H.; Rohl, A. L. Hydrogen Dissociation on Reconstructed ZnO Surfaces. J. Phys. Chem. 1996, 100, 9054-9063.

(37) Becker, T.; Hövel, St.; Kunat, M.; Boas, C.; Burghaus, U.; Wöll, C. Interaction of Hydrogen with Metal Oxides: the Case of the Polar $\mathrm{ZnO}(0001)$ Surface. Surf. Sci. 2001, 486, L502-L506. 